\section{Grażyna Bartkowiak}

Gniezno College Millenium

grazyna.bartkowiak@ue.poznan.pl

\section{Agnieszka Krugiełka}

Poznań University of Technology

agnieszka.krugielka@put.poznan.pl

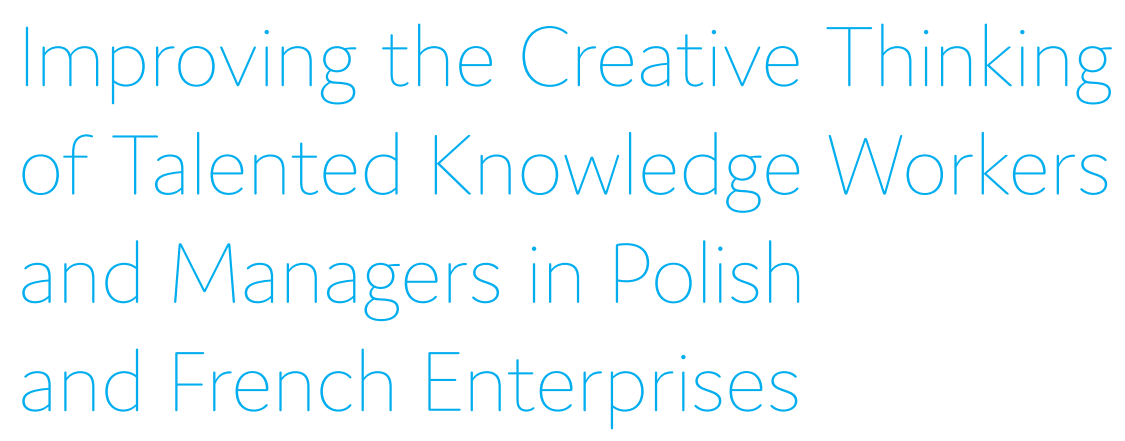

\title{
Abstract:
}

The study considers the issue of creative and participatory activities of employees in the organization in the context of the changing socio-economic expectations, forcing employees, teams and executives to innovative activities. The planned research seeks an answer to the question: What factors attributable to the organization can help to improve the working conditions of knowledge workers classified as "talent", teams of such employees and managers in charge of the work of outstanding employee teams in Poland and France? In order to answer such a question a questionnaire was developed (and subsequently validated) adjusted for purposes of the research and questionnaire research was conducted on a sample of 142 Polish workers in 23 medium- small enterprises, 84 employees from 10 companies in France. Workers considered to be particularly talented in both in Poland and France stressed in the first place the need of approval of deviating from accepted standards 
of work style by the entrepreneurs and board members. Members of the outstanding teams in somewhat greater number in France than in Poland (the variance obtained a criterion for statistical significance) pointed to the "favorable personnel policy" and the ability to obtain additional compensation for an above-average job. In the group of Polish managers "more autonomy" was clearly accentuated in the workplace (the French differed significantly from the Poles in terms of statistics) and already cited "favorable personnel policy". The latter category was also nominated by the bulk of the French managers.

\section{Key words:}

creative thinking, talented employees

\section{Determinants of creative thinking of employees}

\section{1: Introduction}

Although the issue of innovation, creativity and creative thinking has already been - and still is - the subject of numerous considerations in the field of science of organization and management, sociology and psychology and pedagogy, there is a lack of a broader and more in-depth reflection on the role of knowledge and science in the world. In addition, the importance of creative thinking in achieving greater competitiveness, both in the marketplace and in the scale of the individual careers of employees has also been lacking. Furthermore, we may ask which role creative thinking can achieve in removing barriers and optimizing challenges which will benefit organizations.

It is true that the representatives of these sciences do not accept unconditionally the dominant role of technology - especially information technology - in the development of humanity. Technology is only recognized as being instrumental in the progress of civilization. Representatives of social sciences are focusing rather on values (for example, how to build and create sustainable businesses) in determining whether or not technology plays an important role in developing creative thinking and uniting talented groups of employees - who are referred 
to as talent in the literature.' It has been difficult to overestimate the role played by the creation of conditions for the development of creative thinking in the organization. Within this process, an important task remains: breaking down the stereotypes in thinking, which is a task shared by both employees and managers.

The purpose of this study is to identify factors that support creative thinking, both at the level of the organization and also among individual units - particularly among talented employees. This paper now turns to an examination of the results of research concerning the support of creative thinking.

\section{2: Terminology}

Porter (2003) formulated opinion in which creative thinking relates to the operation of innovation. The latter term may be defined as "the implementation of a new or significantly improved product (good or service) or process, a new marketing method, or a new organizational method in business practice, the nature of organization of work or relationship with the environment" (Kożusznik, 2001, p. 170). Innovation, at least in its assumptions, leads to greater efficiency². Schumpeter views innovation similarly while emphasizing, however, that the source of innovation is the discovery and the existence of an entrepreneurial entity (Schumpeter, 1960, p. 41). Drucker (1985) however, writing about innovation, accentuates market success, but innovations without success he called ideas.

Social Studies indicate a link (and sometimes an identity) between innovation and work (Kozielecki, 1992) and creativity (Altszuler, 1972, 1983

\footnotetext{
1. Listwan (2004, p. 41) characterizing the person, saw talent as being attributed to one's above-average ability, creativity, commitment to work and ability to manage people; this involves intelligence, self-control, empathy, the ability to influence, and the ability to motivate. The authors have used interchangeably the term "employee especially gifted" because of its subjective nature.

2. An example of organizational innovation is reengineering, pointed out by Hammer (Sennett, 2006; Zgorzelski, 2002).
} 
\& Nęcka, 1987). Psychology uses another term, which it treats as synonymous with creativity - invention, which is described as "a creative process involving individual, group and organizational creative potential" (Kożusznik, 2010, p. 15 ) $^{3}$.

Elaborating further, a representative of management sciences, J. Brilman (2002) explained the existence of two types of creativity: adaptive creativity, which characterized the improvement of workers, their skills and thus contributed to the improvement of the company's functioning, and secondly, innovational creativity, which defined employees introducing or discovering newand original solutions which becomea source of competitiveadvantage.

From the behavioral perspective put forth by this author, creativity, when it is equated with the ability to think creatively, is a characteristic of operating while considering the results of efforts to introduce new solutions and explore new and effective methods. Creativity facilitates original ideas, which consequently contribute to raising the quality of human life. In this action creativity does not necessarily translate into direct market success and as it is said that the effects of this type of activity can occur only in the perspective of future generations.

\section{3: Determinants of socio-economic knowledge}

In studies devoted to the direction of the development of economics, an abandoning of the classical approach based on the economics of the product - or the calculation of profit popularly called economics quantifiable (tangible economic) - to the innumerable economy (economic intangible) can be seen. Therefore concepts such as the value of intellectual knowledge, competence or reputation arise. Thus defined, the new econ-

3. The issue of the roles of groups, how teams stimulate involvement and create activities, has been documented by many authors (e.g. Brav \& others, 2009; Konradt \&others, 2009), who emphasize the importance of supporting the role of the team and organizational culture. 
omy creates a new economic reality. In fact, in this course spatial-temporal boundaries between market participants disappear and the boundaries' sphere of influence creates new connections and quality relationships. In this situation, the contemporary society is forcing enterprises and institutions dealing with education into a new paradigm of operation.

New challenges and expectations in terms of development of the economy, due to a new diagnosis of the challenges faced by the global economy have been called "conceptual challenges". This term was first used by Alan Greenspan at the University of Connecticut in 1997. According to the proponents of this approach, in recent years there has been a particularly significant increase in the requirements of employees that they cannot only add know-how to established knowledge and obtain information, but also they can develop their capacity for conceptual thinking. Hence, they have the ability to create, analyze, and transform information as well as create effective and efficient interaction with other people (Kożusznik, 2010, p. 25).

\section{4: The development of individuals' creative thinking}

A variety of positions on the formulation of creative activity is found in the literature. An attribute that is considered quite extensively in the literature is reflectivity, which is recognized as the ability to maintain an emotional distance to surrounding human phenomena, to avoid collisions of their own emotions with the subject matter and restrain their involvement in certain activities (Brav et al, 2009; Heatherton et al, 2007). Developing reflectivity involves staff training programs which may involve creating a narrative as a method of developing self-reflection. This helps employees to define and assess their own position with respect to the presented content.

On the other hand, M. Lewicka (1993) and also other authors studying this problem, for example Parker and Griffin (2011), highlight the important 
role of positive mood as an important ally of creative thinking and experiencing positive emotions. According to these authors, positive moods and positive emotions become a kind of mediator, facilitating creative thinking. These contrast with negative moods, which tend to support only the reproduction of previously mastered content. This concept is consistent with the ideas advocated by the author, as cited in Pink (2005). Pink states that the importance of the right hemisphere of the brain, responsible for experiencing emotions and moods, has been emphasized.

In practice, this means not only striving to reduce and minimize the emotional strain during work - especially creative work - but also a deliberate action on the part of executives to induce positive emotions that harness talents (for example, by rewarding effort, positive mobilization, shaping positive vision, as is the case for the transformation and actual leadership (Avolio \& others, 2004; Avolio, Gardner, 2005; Bartkowiak, 2010). Similarly, creative thinking and inspiration play an important role in problem-solving and support creative interaction. Conflicts within groups clearly reduce motivation (Konradt\& others 2009, pp. 333-338).

Research conducted recently by an Italian teacher (Simbuli et al, 2011) has shown a relationship between a sense of agency (also called self- efficacy), and creative involvement in work.4 By collecting their own positive experiences that can be reinforced by specific manifestations of organizational culture and remembering such things as certificates and prizes awarded during a special ceremony employees can reinforce self-efficacy. Building a sense of agency plays an extremely important role in organizational structure, called the system of "self". The self in the literature is referred to as a "dynamic and orderly arrangement of thoughts, feelings and motives relating to their social relations and personal relationship to

4. Similar conclusions were reached in their research conducted among the employees of the company by Bakker, Albrech, Leiter (2011). Among Polish authors a relatively complete analysis of efficacy as a determinant of success in the operation was carried out by the already quoted author, M. Adamiec (2000, 2010). 
the world" (Holy, 2006, referenced by Strelau \& Doliński, 2010, p.738). It includes the following elements:

- Cognition: self-knowledge

- Value of the self: self-esteem,

- Implementation of the self: self-regulation (Headherton and others, 2007).

The first two items characterize the structure of the self, and the last one refers to the self-considered as a process. Obuchowski has identified self-subjective and concerned self-intentional. According to this author, self-subjective is, as a phenomenon, secondary to concerned self-intentional (Obuchowski, 2003, pp. 162-177) and functions by allowing one to distance themselves from their immediate needs and desires. In other words, it does not succumb to the influence of external factors while operating within an organization. Self-subjective, constituting the content and structure of the system, is under the control of self-intentional. In this way, we can talk about the autonomy of the individual (Obuchowski, 2000, p. 320) in fulfilling their own aspirations, creating a vision of their own career and professional success. Self-subjective involves two processes: self-reflection, as the ability to self-discover, and recognition. Likewise, self in relation to the environment and self-regulation, as executive functions, involve the ability of individuals to exercise control over their thoughts, feelings, and actions (Mc Donald, 2000, referenced by Oleś \& Drat-Ruszczak, 2010, p. 712).

Conditions for efficient operation associated with the process of self-regulation assure self-efficacy. This belief does not guarantee certainty of success, but rather a kind of acquiescence which allows for success to be achieved and for the development of specific competencies (Bartkowiak, 1999, p. 11). The notion of self-efficacy results in an individual taking action, being perseverant, showing effort and displaying appropriate feelings that accompany this activity (Oleś \& Drat-Ruszczak, 2010, p. 714).

The conviction of self-efficacy is associated with efficacy, which is understood as personal effectiveness in the realization of goals. In the 
literature, this term is associated with terms such as initiative, creativity, intelligence and entrepreneurship. It includes three elements: the circumstances of the action, understanding their goals and values, and effective action (Bartkowiak, 2010, pp. 161-162).

Similarly, as in the case of exploring the world, knowledge about ourselves is apprehended in the form of specific patterns of self, such as a conviction of one's own independence. These schemes become part of the standard, which in turn are part of the self-real, self-ideal or self-duty. The existence of self-ideal allows humans to have aspirations and motivation to achieve ideals in different areas of life (Carvey, 2001). Therefore, the discrepancies between the self-real and self-perfect, or between self-identified and self-duty (created in the process of socialization), induce different emotional states ${ }^{5}$. Realizing the standards of self- ideal increases a sense of satisfaction, fulfillment and even joy.

The almost classical assumption of Khan and Katz (1979), postulates that executives on the second level of management (operational managers) play the most important role (75\%), provide social skills (competencies), and thus communicate, motivate, evaluate management conflict, negotiation and coping with stress. In such situations, the activity of the creative manager is reduced to stepping up the teams' motivations to think creatively. It is, in the opinion of B. Kożusznik and M. Adamiec (2001), a position of inspirational role manager. Motivating teams to work creatively seems to result in underestimating task and task for particular rank, when working in teams is granted as a priority (Bartkowiak, 2011, pp. 52-65).

In addition, studies have shown that although there is no reason to oppose the ability to think creatively and to develop social competence, they

5. This topic is explained in a communicative manner by ns Thorry's and Higgin's Self-orientations theory $(1987,1996)$, in which the thought of assumptions emphasis a large discrepancy between the Self-ideal and Self-real generated emotional states such as depression, grief, and depression, while large discrepancies between Self-real and Self-duty, accompanied by fear of the fear of punishment, guilt. 
rarely occur in the same person (Trzebiński, 1976). Because of this, however, managerial work, assuming that it impacts on people, competence is especially important and seems to inspire employees to creative activity, and do creative work.

\section{Research on organizations' creative thinking \\ 2.1: Methodological assumptions and research organization}

A consideration of the diversity of views on how creative activities are fostered among employees in organizations, as well reflection on conditions from the point of view of individuals and teams of employees, resulted in the formulation of the following research questions:

1) What are the factors attributable to the organization that can contribute to the improvement of workers who are classified as "talents"?

2) Which conditions should motivate an organization to improve the work of outstanding employees?

3) Which factors may facilitate the work of managers in charge of distinctive teams of employees?

Obtaining answers to these questions required planning and execution of a particular test procedure consisting of two steps. In the first stage of the study (142 and 84 persons) - workers employed on independent positions classified in the company as talents - 20 and 12 teams of employees (between 6-8 people each) and their managers (respectively 67 and 54 people) determined the list of factors that improve the work of talented employees and teams and allow them to achieve above-average results and motivate managers to streamline directing their work, exchange their opinions and other significant factors. Next, these factors were narrowed down, by competent judgement, to those that occurred in at least $50 \%$ of the 
statements. In this way, three short lists were established, containing respectively of 5 and 4 (see tables $1 \& 2$ below). The staff were employed in 23 medium-sized enterprises and two banks in Poland and 10 medium-sized enterprises that were similar (e.g. shopping and services) and two banks in France. They were deliberately chosen. In addition, short interviews were carried out to verify the accuracy of answers to the questionnaire. The study was conducted in the months of July and August, 2012. All participants had completed higher education.

\section{2: Research results}

For employees operating on independent positions, classified (by managers) as particularly talented (talents), significant factors that may improve work and are attributable to the distinguished organization are as follows:

- acceptance by the management of individual work styles, personal values of talented people, and no need for talents to adapt to the formal aspects of labor discipline;

- a sense of the meaning of work in the context of an understanding of its importance to the company's strategy and the broader social terms;

- the need to fulfill the obligations arising not only from a contract of employment, but from the psychological contract between the employer and employees;

- employers creating flexible forms of work;

- allowing the building of individual career paths. 
Table 1. Factors facilitating the work of talented employees (based on their reviews)

\begin{tabular}{|l|l|l|l|l|}
\hline Factors category & $\begin{array}{l}\text { Poles } \\
(\mathrm{N})\end{array}$ & $\begin{array}{l}\text { Poles } \\
(\%)\end{array}$ & French (N) & French (\%) \\
\hline $\begin{array}{l}\text { Acceptance of an } \\
\text { individual work style }\end{array}$ & 142 & 100.00 & 84 & 100.00 \\
\hline $\begin{array}{l}\text { Having a sense of pur- } \\
\text { pose in their work }\end{array}$ & 125 & 88.00 & 49 & 58.33 \\
\hline $\begin{array}{l}\text { Maintaining a psycho- } \\
\text { logical contract }\end{array}$ & 94 & 66.19 & 49 & 58.33 \\
\hline $\begin{array}{l}\text { Having flexible forms } \\
\text { of cooperation }\end{array}$ & 79 & 55.63 & 42 & 50.00 \\
\hline $\begin{array}{l}\text { Allowing for individual } \\
\text { career paths }\end{array}$ & 71 & 50.00 & 41 & 48.81 \\
\hline
\end{tabular}

\section{Source: own study.}

The table shows that the subjects in both Poland and France are measuring their expectations of the employer by a similar hierarchy. In both nations, "the acceptance of individual work style" turned out to be the most important, followed by a group of Poles who pointed to "a sense of meaning of work" and a group of French who cited "keeping the findings of psychological contract".

In individual interviews especially skilled workers in Poland (56\%) pointed to the importance of fair, but at the same time professional, assessment of their work, and (circa 44\%) emphasized that employers are not interested in giving other employees "material incentives" (e.g. bonus extras, internship, gradually raising salaries, etc.).

Noteworthy is the fact that there was a kind of ignorance about the importance of working relationships with other employees. One gets the impression that these relationships were minor in nature, in the context of the overall assessment of the working conditions. Rating expression showed that in most cases, except for two people with a pro-social motivation, surveyed workers displayed self-centered motivation. 
This view was confirmed by representatives of the Management Board (consisting of employers) in Polish enterprises, who pointed to the isolation that characterized a group of employees from their colleagues, mentioned their extreme individualism, and sometimes stated that they were narcissistic. These reviews confirm the existing evidence that there is a need for an individual approach to employees who are especially gifted.

Turning now to the analysis of the questionnaire executives deemed the most effective in motivating creativity, committed and creative work it can be seen that we could distinguish the following categories of statements indicating the conditions to be met by the organization (employers) in motivating the team to a more committed operation. These criteria included:

- a favorable personnel policy, fostering the employees' development; this involves creating opportunities for promotion, equitable policy of employees rewarding, keeping employment obligations made at the time; - the use of specific, additional forms of reward for outstanding teams (e.g. attractive trips abroad, etc.);

- reliable assessment of the contribution of work, of both individual employees and work teams;

- improvement of working conditions and wages resulting from the physical effects of worked out. 
Table 2. Factors facilitating the work of team members achieving outstanding results (in executives'opinion )

\begin{tabular}{|l|l|l|l|l|}
\hline Factors category & $\begin{array}{l}\text { Poles } \\
(\mathrm{N})\end{array}$ & $\begin{array}{l}\text { Poles } \\
(\%)\end{array}$ & French (N) & French(\%) \\
\hline $\begin{array}{l}\text { Favourable personnel } \\
\text { policy }\end{array}$ & 50 & 74.62 & 54 & 100.00 \\
\hline $\begin{array}{l}\text { Additional forms of } \\
\text { reward }\end{array}$ & 47 & 70.15 & 54 & 100.00 \\
\hline $\begin{array}{l}\text { A thorough assess- } \\
\text { ment of the contribu- } \\
\text { tion of labor }\end{array}$ & 43 & 64.18 & 33 & 61.11 \\
\hline $\begin{array}{l}\text { The relationship } \\
\text { between labor input } \\
\text { and elaborated works } \\
\text { effects }\end{array}$ & 43 & 64.18 & 33 & 61.11 \\
\hline
\end{tabular}

\section{Source: own study.}

As we can see in the table, staff stressed the importance of the subjective relationship between self-involvement, obtained by the company, profit, and income earned from work. When we measure conditions to improve, remove barriers and optimize their own work, a team of surveyed managers identified the following factors:

- greater autonomy in personnel decisions regarding the team which is managed; this involves the impact of the choice of the people, from rewarding, promotions and wage increases;

- greater autonomy in their work;

- HR policy focused on building long-term intellectual and social capital in the company;

- accepting a broader perspective on the company's strategy, which involves growth of key competences, which should be linked to concern about the increased competence of individual employees; 
- eliminating problematic attitudes that owners of the company have, such as focusing solely on profit in a relatively short period of time, overlooking the fact that the company's employees are its most valuable resource.

Table 3. Factors that empower managers running distinctive employee teams (based on their reviews)

\begin{tabular}{|l|l|l|l|l|}
\hline Factors Category & $\begin{array}{l}\text { Poles } \\
(\mathrm{N})\end{array}$ & $\begin{array}{l}\text { Poles } \\
(\%)\end{array}$ & French (N) & French (\%) \\
\hline $\begin{array}{l}\text { Greater autonomy of } \\
\text { work }\end{array}$ & 67 & 100.00 & 27 & 50.00 \\
\hline $\begin{array}{l}\text { Favorable personnel } \\
\text { policy }\end{array}$ & 67 & 49.25 & 27 & 66.66 \\
\hline $\begin{array}{l}\text { Widely recognized (in } \\
\text { the long term) strate- } \\
\text { gy of the company }\end{array}$ & 33 & 65.67 & 27 & 50.00 \\
\hline $\begin{array}{l}\text { Quickly achieving a } \\
\text { profit should not be } \\
\text { the primary factor } \\
\text { determining the opera- } \\
\text { tion of the company }\end{array}$ & 44 & & 50.00 \\
\hline
\end{tabular}

\section{Source: own study.}

The data obtained show a greater explicitness in the opinion of Polish managers, compared with the French concerning factors that could contribute to the improvement of their work. In the case of the Polish group the important factors were: greater autonomy at work, as well as favorable personnel policies - which were factors pointed out by all managers participating in the research. Among the French managers the most popular opinions turned out to be the second of the listed categories (selected by about $67 \%$ of respondents).

Speaking about their own work, Polish managers gave differing statements. The vast majority emphasized that they like their job and cannot imagine that they could do anything else. Some(50\%) claimed that in moti- 
vating the team they have a vision of the situation of the target, while others said that their vision occurs during the operation of the team and is simultaneously created by that team (also 50\%).

Some of the respondents commenting on their own work emphasized the role of their own involvement (circa 67\%), the importance of their impact on the selection of team (circa 33\%), their determination in lieu of family life, and still others pointed to the expectation of success, and then their experience as a factor especially motivated others to action. Most of the answers, as it was in the case of particularly talented employees could be deduced motivated individual, usually more self-centered than intrinsic motivation or pro-social.

At this point, it is worth mentioning that a fairly skeptical view was expressed by less than 50\% of respondents - executives from Poland that is, indicating that low autonomy is associated with low levels of creativity are evident in private, medium-sized Polish enterprises, as well as in corporations. In other words, in both corporations and smaller companies employees were expected to achieve goals that were impossible to meet and, as a result, creativity suffered. Some interviewed subjects indicated directly that the condition of the property as a factor that "condemns them to an employment", hence limiting their creativity.

\section{Summary}

In conclusion, comparing the three groups that participated in the research, each of which included subjects within Poland and France, it is important to, first and foremost, pay attention to the discrepancies between the employees who were recognized as particularly gifted - members of outstanding teams - and managers directing the teams. Employees recognized for particular talent in both Poland and France stressed, first of all, the need to gain acceptance of their deviation from accepted standards of work style by 
the Management Board. Members of the outstanding teams in somewhat greater numbers in France than in Poland found as essential "favourable personnel policy" and the possibility of obtaining additional compensation for an above average job.

The group of Polish managers clearly accentuated "more autonomy at work" and "favorable personnel policy". This second category was also nominated by the bulk of the French managers. There are differences between talented people working on independent positions, employees in outstanding teams and also managers leading the teams. In the last two groups, they (i.e. workers from outstanding teams and managers) paid attention to the material forms of rewarding their activity involved, while among those employees working in independent positions rewards took the form of the doing the same job. 


\section{References}

Adamiec, M. (2000) Human Resource Management. Warsaw: Arkade.

Adamiec, M (2010) Dynamics (of) knowledge, Chaos, Culture [in:] B. Kożusznik (Eds.),

Psychological aspects of innovation. Chowanna, Volume 2 (35), published by the University of Silesia, Katowice.

Altszuller, H (1972) Algorithm inventions. Warsaw: Omega.

Altszuller GS (1983) Elements of the theory of creative engineering. Warsaw: WNT.

Avolio, B.J., Gardner, W.L. (2005) Authentic leadership development: getting to the root of positive forms of leadership. Leadership Quarterly, No.15.

Avolio, B.J., Gardner, W.L., Walumbwa, F.O. \& Luthans, F., May, R.D. (2004) Preface [in:] Authentic leadership theory and practice: Origins, effects and development. San Francisco.

Bubble, A. (2007) Psychological counseling careers. Poznań: Print-B.

Bakker, A.B., Albrecht, S.L. \& Leiter, M.P. (2011) Key questions work engagement. European Journal of Work and Organizational Psychology, 20 (1).

Bartkowiak, G. (2010) Psychology in Management, New look. Poznań: Ed. University of Economics.

Bartkowiak, G. (2009) Man at work. From stress to success in the organization. Warsaw: PWE. 
Bartkowiak, G., Krugiełka, A. (2009) The team-work as a background of modern management concepts activity. Management, Vol. 13, no 2, pp. 52-65.

Bartkowiak, G. (2011) Corporate social responsibility in terms of theoretical and empirical. Warsaw: Difin.

Brav, A., Andersson, K. \& Lantz, A. (2009) Group initiative and self-organizational activities in industrial work performance. European Journal of Work and Organizational Psychology, 18, (3).

Brilman, J. (2002) Modern management concepts and methods. Warsaw: PWE.

Drucker, P. (1985) The discipline of innovation. The innovative enterprise, August edition.

Carver, C.S., (2001) Affect and the Functional Bases of Behavior, the Dimensional Structure and Effective Experience. Personality and Social Psychology Review, 5.

Heatherton, T.E., Krendl, A.C., Macrae, C.N. \& Kelly, W.M. (2007) A social brain sciences approach is understanding the self [in:] C. Sedikides, S.J. Spencer (ed.), The self. New York: New York Psychology Press.

Higgins, E.T. (1987) Self - discrepancy: a Theory Relating Self and Affect. Psychological Review, 94.

Higgins, E.T. (1996) The "Self-digest": Self-knowledge serving self-regulatory functions, Journal of Personality and Social Psychology, 71.

Katz, D. \& Kahn, R.L. (1979) The social psychology of organizations. Warsaw: PWN. 
Konradt, L., Andersen, P. \& Ellwart, T. (2009) Self-leadership in organizational teams: a multilevel analysis of moderators and mediators. European Journal of Work and Organizational Psychology, 20 (3).

Kozielecki, J. (1992) Creativity and problem solving [in:] M. Materska, T. Tyszka, Psychology and cognition. Wrasaw: PWN.

Kożusznik, B. \& Jezierski, T. (1994) Psychology improvement teams. Katowice: University of Silesia.

Kożusznik, B. (2010) The key role of psychology in supporting and stimulating innovation [in:] B. Kożusznik (Eds.), Psychological aspects of innovation. Chowanna, vol.2 (35), Katowice: University of Silesia.

Lewicka, M. (1993) The actor and the observer: psychological mechanisms of deviations from rationality in thinking every day. Polish Psychological Association, Laboratory Publishing, Warsaw, Olsztyn.

Lewicki, A. (2002) Some of the problem behavior theory in: A. Lewicki (Eds.), Clinical Psychology. Warsaw: PWN.

Listwan, T. (ed.) (2004) Talent Management. ed., 2, Warsaw: CH Beck.

Nęcka, E. (1987) The creative process and its limitations. Cracow: Eds. Jagiellonian University

Obuchowski, K. (2000) By the galaxy needs. PWN: Warsaw.

Obuchowski, K. (2003) Man intentional. Warsaw: PWN. 
Oles, P. \& Drat-Ruszczak, K. (2010) Personality [in:] J Strelau, D. Dolinski (Eds.), Psychology of academics, Volume 1. Gdańsk: GWP.

Parker, S.K. \& Griffin, M.A. (2011) Understanding active psychological states: Embedding engagement in a wider normological net and closer attention to performance. European Journal of Work and Organizational Psychology, 20 (1).

Pink, D. (2005) A Whole New Mind: Moving from the Information Age to the Conceptual Age. New York: Penguin Group,

Porter, M. (2003) Attitudes, values and beliefs and macroeconomics prosperity [in:] Harrison, L. \& Huntington, S. (eds.), Culture Matters, Poznan: Profit and S-ka.

Schumpeter, J. (1960) The theory of economic development. Warsaw: PWN.

Sennett, R. (2006)Corrosion of character: personal consequences of work in the new capitalism. Warsaw: Publisher Literary Muse.

Simbuli, S., Guglielmi, D. \& Schaufeli, W.B. (2011) A three -wave study of job resources , self- efficacy and work engagement among Italian schoolteachers. European Journal of Work and Organizational Psychology, 20(3).

Strelau, J. \& Dolinski, D. (eds) (2010) Psychology of academics, Volume 1. Gdańsk: GWP.

Toffler, A (1981) The Third Wave. New York: Bantam Books.

Toffler, A. (1990) Powershift : Knowledge, Wealth and Violence at the Edge of the 21st Century. New York: Bantam Books. 
Trzebiński, J. (1976) Personality and conditions of creativity [in:] J. Reykowski (Eds.), Personality and pro-social behavior of people. Warsaw: PWN.

Zgorzalski, M. (2002) Hamburgers with sacred cows. Sketches of American Management Theory and Practice. Cracow: Walters Kluver Publishing House. 
